\title{
Ethyl-Iophenoxic acid as a serum marker for oral baiting of carnivorous marsupials
}

Ruth Pye ${ }^{1}$; David Nichols ${ }^{2}$; Amy T. Gilbert ${ }^{3}$; Andrew S. Flies ${ }^{1}$

${ }^{1}$ Menzies Institute for Medical Research, University of Tasmania, 17 Liverpool St, Hobart, Tasmania 7000, Australia

${ }^{2}$ Central Science Laboratory, College of Sciences and Engineering, University of Tasmania, Sandy Bay, Tasmania 7005, Australia

${ }^{3}$ US Department of Agriculture, Animal and Plant Health Inspection Service, Wildlife Services, National Wildlife Research Center, 4101 LaPorte Ave., Fort Collins, Colorado, 80521, USA

\section{ABSTRACT}

Context: Ethyl-Iophenoxic acid (Et-IPA) has been widely used as a bait biomarker to determine oral bait consumption by vertebrate wildlife species. Oral bait vaccines have been delivered to numerous wildlife species to protect them from disease. The Tasmanian devil (Sarcophilis harrisii), the largest extant carnivorous marsupial species, is threatened by the transmissible cancers known as devil facial tumour disease (DFTD). Development of a protective DFTD vaccine is underway, and an oral bait has been proposed to deliver the vaccine in the wild. The bait delivery system requires a biomarker that can be detected for several months postconsumption in Tasmanian devils.

Aim: To determine the suitability of Et-IPA as a bait biomarker in the Tasmanian devil.

Method: Two Tasmanian devils were fed $50 \mathrm{mg}$ Et-IPA (4.5 to $7.1 \mathrm{mg}$ Et-IPA/kg bodyweight). Liquid chromatography with tandem mass spectrometry (LC-MS/-MS) was used to directly 
measure Et-IPA in baseline serum samples and samples collected on days 1, 14, 26 and 56 post-baiting.

Key results: Both devils retained serum Et-IPA concentrations at two orders of magnitude above negative control sera when this study concluded.

Conclusions: Et-IPA is a useful bait biomarker for Tasmanian devils and can be included in future DFTD bait vaccine field trials to determine bait vaccine uptake. 


\section{INTRODUCTION}

Vaccines, medications and toxicants have been delivered to vertebrate wildlife in baits for at least 50 years to prevent or treat disease, or to suppress populations of invasive or unwanted species (Baer 1976, Qureshi et al. 1994, Philip 2020). Central to understanding the efficacy of these control methods is the ability to monitor bait consumption. A variety of biomarkers, in particular tetracycline, rhodamine B, and derivatives of iophenoxic acid have been included in baits to identify bait consumption by target and nontarget species.

Biomarkers should be non-toxic, palatable, easily incorporated into a bait, and detectable by a minimally invasive method and for a useful length of time post-ingestion (Jacoblinnert et al. 2021). Tetracycline and tetracycline-derivatives such as doxycycline are antibiotics that accumulate in the teeth and bones of animals when ingested and have been identified for up to 150 days post-ingestion (Van Brackle et al. 1994). Their use as biomarkers relies on invasive methods i.e. tooth extraction or culling, for detection. Release of antibiotics into the environment is another drawback associated with tetracyclines' use. Rhodamine $\mathrm{B}$ has been widely used as a bait biomarker in mammals and can be detected in whiskers and hair for between 28 and 196 days in different species (Fisher 1999). Limitations associated with rhodamine B include palatability and difficulty of use in large production facilities (Linton Staples pers. comm.).

Ethyl-Iophenoxic acid (Et-IPA), a widely available derivative of IPA, has a long history as a useful bait biomarker in a wide variety of mammalian species. Serum Et-IPA is detected indirectly by measuring levels of protein bound iodine, or directly using liquid chromatography-mass spectrometry (LC-MS), or liquid chromatography with tandem mass spectrometry (LC-MS/-MS). These methods have detected Et-IPA in different species for up to 273 days (Ballesteros et al. 2013). Et-IPA has previously been tested in only 
two marsupial species, swamp wallabies (Wallabia bicolor) (Fisher et al. 1997) and brushtail possums (Trichosurus vulpecula) (Eason et al. 1994). The separate studies used the indirect method of Et-IPA detection, and both found plasma iodine levels had returned to baseline levels by day 7 . The authors concluded that marsupials might have a physiological pathway that differs to eutherian mammals and results in faster excretion of Et-IPA (Fisher et al. 1997). Both studies concluded that et-IPA was not a useful biomarker in marsupials because of the short window of detection. Wallabies and possums are from the order Diprotodontia, which are largely herbivorous. No Et-IPA trials have been conducted to date on the carnivorous marsupial order Dasyuromorphia.

The Tasmanian devil is a carnivorous marsupial (Figure 1) threatened by the transmissible cancers that cause devil facial tumour disease (DFTD). Research is underway to develop an oral bait platform on which to deliver a protective devil facial tumour disease vaccine (Flies $e t$ al. 2020). The proposed DFTD oral bait vaccine draws on many aspects of the comprehensive oral rabies bait vaccine programs that use oral bait vaccines to immunise wildlife rabies reservoirs (reviewed in (Müller et al. 2015). This includes the use of IPA as the bait vaccine biomarker (Berentsen et al. 2019).

In this study we tested the suitability of Et-IPA as a bait marker in Tasmanian devils, using LCMS/-MS to directly measure serum Et-IPA. The LC-MS/-MS method described here is similar to recently published methods in (Berentsen et al. 2019) and (Berentsen et al. 2020).

\section{METHODS}

\section{Animals, IPA administration and blood sample collection}

Two captive Tasmanian devils, housed individually in enclosures in accordance with the guidelines of the Department of Primary Industries, Parks, Water and Environment of Tasmania were used in this study. TD1 was a 4 year old male, body weight $11 \mathrm{~kg}$, and TD2, a 
5 year old female, body weight $7 \mathrm{~kg}$. The devils were housed individually in $100 \mathrm{~m}^{2}$ enclosures. Water was provided ad libitum and devils fed once daily. Their diet was predominantly possum and wallaby meat, with occasional chicken and rabbit meat. All animal procedures were approved by the University of Tasmania Animal Ethics Committee under 23220 and A0017550.

200 mg Et-IPA (a-Ethyl-3-hydroxy-2,4,6-triiodohydrocinnamic acid, CAS 96-84-4, Sigma Aldrich) was dissolved in $4 \mathrm{ml}$ edible corn oil, heated to $90^{\circ} \mathrm{C}$ to aid dissolution, then returned to room temperature. Oral baits were prepared by inoculating $1 \mathrm{~mL}$ of the solution (containing $50 \mathrm{mg}$ Et-IPA) into a dead day-old chicken (Gallus gallus) and fed to each devil on day 0 . The dose range of Et-IPA administered to the devils was therefore between $4.5 \mathrm{mg} / \mathrm{kg}$ and $7.1 \mathrm{mg} / \mathrm{kg}$ body weight.

The baseline blood sample was collected from each devil more than 3 months prior to the EtIPA administration, and subsequent blood samples were collected on days 1, 14, 26 and 56 post-baiting. Blood collection was carried out under general anaesthesia following methods described in (Tovar et al. 2017). $3 \mathrm{~mL}$ blood was collected from the jugular vein into clot activating tubes. After a minimum of 30 minutes to allow for clot formation, samples were centrifuged at $1700 \mathrm{G}$ for 5 minutes and the serum pipetted into $1.5 \mathrm{~mL}$ eppendorf tubes and stored at $-80^{\circ} \mathrm{C}$. Serum from a separate captive devil, housed under conditions described above, had previously been collected and stored at $-80^{\circ} \mathrm{C}$, and was used for the external calibration step of the Et-IPA serum detection method. Serum samples were analysed as they were collected rather than at the end of the trial.

\section{$\underline{\text { Et-IPA detection in serum }}$}

\section{Sample Preparation:}

Serum samples were extracted based on the protocols of (Bruce et al. 2009). $200 \mu \mathrm{L}$ of serum was taken and extracted with $800 \mathrm{uL}$ of $\mathrm{MeOH}$ :Acetone $(1: 1, \mathrm{v} / \mathrm{v})$. The mixture was 
vortexed for 30 seconds then placed at $-20^{\circ} \mathrm{C}$ for 30 minutes to aid in protein precipitation. The solution was then centrifuged at $15,000 \mathrm{rpm}$ for $12 \mathrm{~min}$ at $4{ }^{\circ} \mathrm{C}$, and the supernatant transferred to an ultra-performance liquid chromatography (UPLC) vial for analysis. Blank extractions were included with samples, together with a baseline sample recovery (spike) sample. The spike sample was produced from baseline serum, where $50 \mu \mathrm{L}$ of the extraction solution was substituted with a $200 \mathrm{ng} / \mathrm{mL}$ working standard of Et-IPA.

For quantitation of Et-IPA in serum samples, a matrix matched external calibration was used. Two serum samples from a non-treatment devil were utilised (neat and high spike). The neat serum sample was extracted as described above. The high spike sample was extracted where $300 \mu \mathrm{L}$ of the extraction solution was substituted with a $2000 \mathrm{ng} / \mathrm{mL}$ working standard of EtIPA. Proportions of the neat and high spike serum extracts were then combined in various ratios to produce 8 matrix matched external calibration standards over the range 0.5 to $5000 \mathrm{ng} / \mathrm{mL}$ Et-IPA in serum. Where measured serum concentrations exceeded the external calibration range, sample extracts were diluted with baseline serum extract and reanalysed.

\section{Sample Analysis:}

Sample analysis was undertaken using a Waters Acquity ${ }^{\circledR}$ H-class UPLC system (Waters Corporation, Milford, MA). Chromatography was performed using a Waters Acquity VanGuard C18 pre-column $(5 \times 2.1 \mathrm{~mm})$ coupled to a Waters Acquity C18 column $(100 \times 2.1 \mathrm{~mm} \times 1.8 \mu \mathrm{m}$ particles $)$. The UPLC was coupled to a Waters Xevo TQ triple quadrupole mass spectrometer (Waters Corporation). The UPLC was operated with a mobile phase consisting of $1.0 \%(\mathrm{v} / \mathrm{v})$ Acetic acid in water (Solvent A) and Acetonitrile (Solvent B). Elution utilised a gradient program beginning with $50 \%$ B held for 0.5 min, moving to $95 \%$ B at $4.0 \mathrm{~min}$, held for $1.0 \mathrm{~min}$. At $5.5 \mathrm{~min}$, composition was returned to $50 \% \mathrm{~B}$ and the column equilibrated for a further 3 minutes. The flow rate was $0.35 \mathrm{~mL} / \mathrm{minute}$ and the column was held at $35^{\circ} \mathrm{C}$. Injection volume was $2 \mu 1$. Typical retention time for Et-IPA was $3.0 \mathrm{~min}$. 
Analyses were undertaken using simultaneous single ion monitoring (SIM) and multiple reaction monitoring $(\mathrm{MRM})$ in negative electrospray ionisation mode. Electrospray ionisation was performed with a capillary voltage of $2.8 \mathrm{kV}$, and individually optimised cone voltages and collision energies for each MRM transition, as described below. The desolvation temperature was $450^{\circ} \mathrm{C}$, nebulising gas was nitrogen at $950 \mathrm{~L} / \mathrm{h}$ and cone gas was nitrogen at $50 \mathrm{~L} / \mathrm{h}$. SIM analysis for IPA utilised the deprotonated molecule $[\mathrm{M}-\mathrm{H}]-\mathrm{m} / \mathrm{z})$ 570.70 with a cone voltage of $15 \mathrm{~V}$. MRM transitions monitored for IPA were $[\mathrm{M}-\mathrm{H}]-(\mathrm{m} / \mathrm{z})$ 570.70 to 442.80 (cone voltage $15 \mathrm{~V}$; collision energy $17 \mathrm{~V}$ ) and (m/z) 570.70 to 126.80 (cone voltage $15 \mathrm{~V}$; collision energy $13 \mathrm{~V}$. Dwell time per channel was $161 \mathrm{~ms}$.

\section{RESULTS}

Both of the devils readily accepted and consumed the Et-IPA marked baits. TD1 consumed the entire piece of Et-IPA laden meat within 30 minutes of it being offered and TD2 consumed it immediately.

External, matrix matched calibration was successfully demonstrated over the concentration range 0.5 to $5000 \mathrm{ng} / \mathrm{mL}$ of Et-IPA in devil serum. A linear correlation coefficient of 0.9974 $+/-0.0013(\mathrm{n}=3)$ was achieved, with an example shown in Figure 2. Recovery of Et-IPA from a $50 \mathrm{ng} / \mathrm{ml}$ spike into blank devil serum was achieved at $70+/-3 \%(\mathrm{n}=3)$ over the course of three independent (inter-day) analyses.

Analysis of baseline serum samples for both TD1 and TD2 demonstrated no sample analysis interferences (Figure 3A). The highest concentration of serum Et-IPA $(13,624 \mathrm{ng} / \mathrm{mL})$ was observed for TD1 on day 1, post-ingestion (Figure 3B). This was high enough to require dilution of the serum extract with baseline serum extract, to maintain the appropriate matrix effect and get the sample into the calibration range. 
Both devils retained quantifiable levels of serum Et-IPA at day 56 post-baiting when this study concluded (TD1 735 ng/mL; TD2 94 ng/mL, Figure 4).

\section{DISCUSSION}

This study is the first to demonstrate that Et-IPA is a useful biomarker in a marsupial species. We used the LC-MS/-MS method to directly detect Et-IPA in the serum of Tasmanian devils for eight weeks following oral administration of between 4.5 and $7.1 \mathrm{mg} / \mathrm{kg}$ Et-IPA. In previous studies, serum iodine was not detectable in two other marsupial species, swamp wallabies and brushtail possums, 7 days after Et-IPA ingestion despite administration of relatively high doses of Et-IPA (up to $30 \mathrm{mg} / \mathrm{kg}$ for wallabies). It was hypothesized the short window of iodine detection was due to a difference in Et-IPA metabolism between marsupial and eutherian mammals (Fisher et al. 1997). Those studies used the indirect method of serum iodine measurement to determine the duration of Et-IPA as a biomarker in contrast to the more sensitive LC-MS/-MS method described here.

Tasmanian devils are carnivorous in contrast to the herbivorous wallabies and omnivorous possums, which may have some effect on Et-IPA metabolism. We suggest that the LC-MS/MS method may also detect Et-IPA in these species for a useful length of time. We expect that Et-IPA would be detected in devils beyond 56 days (when this study concluded) due to the serum Et-IPA in the twos devils at day 56 measuring two orders of magnitude above the minimum in the standard curve $(0.5 \mathrm{ng} / \mathrm{mL})$. Furthermore, the serum Et-IPA concentrations in each devil decreased by approximately 1.5 orders of magnitude over the 2-month study.

The LC-MS/-MS methods described here used a similar instrumental approach to that described previously in (Berentsen et al. 2019), but we used a different experimental protocol, most notably with our approach to quantitation. The (Berentsen et al. 2019) study, which detected and differentiated between Et-IPA and methyl-IPA in small Indian 
mongoose serum samples, used external calibration in a water matrix and then corrected for recovery and matrix effect by the use of methyl-IPA as the internal standard. Our approach was to use fully matrix matched external calibration of Et-IPA in devil serum. This showed no EtIPA in the negative controls but a clear signal in serum containing the Et-IPA spike and serum from devils consuming Et-IPA.

Methyl-IPA, another derivative of IPA that differs to the more widely used Et-IPA has been incorporated into field trials that require distinction between the timing and/ or location of bait uptake (Berentsen et al. 2020). We could not identify any commercial suppliers of methyl-IPA at this time, precluding its broader use for temporal and spatial bait uptake field studies. Rhodamine B has been trialled in Tasmanian devils (Bell et al. 2020) and was detectable in whiskers when tested a minimum of two weeks post-ingestion. If the limitations of rhodamine B i.e. palatability and ease of incorporation into bait matrix, can be overcome, it could be used in combination with Et-IPA for such studies. Future oral DFTD bait vaccination trials for Tasmanian devils that include an immune priming component followed by an immune boosting component would benefit from two different biomarkers. 


\section{Acknowledgements}

We thank Ginny Ralph for taking care of the captive devils used in this trial.

\section{Conflict of interest}

The authors declare no conflicts of interest

\section{Literature Cited}

Baer GM. 1976. The oral rabies immunization of foxes and dogs with sausage baits. Developments in Biological Standardization 33:417-23.

Ballesteros C, Sage M, Fisher P, Massei G, Mateo R, De La Fuente J, Rossi S \& Gortázar C. 2013. Iophenoxic acid as a bait marker for wild mammals: efficacy and safety considerations. Mammal Review 43:156-166.

Bell O, Jones ME, Ruiz-Aravena M, Hamede RK, Bearhop S \& Mcdonald RA. 2020. Agerelated variation in the trophic characteristics of a marsupial carnivore, the Tasmanian devil Sarcophilus harrisii. Ecology and Evolution 10:7861-7871.

Berentsen AR, Chipman RB, Nelson KM, Gruver KS, Boyd F, Volker SF, Davis AJ, Vos A, Ortmann S \& Gilbert AT. 2020. Placebo Oral Rabies Vaccine Bait Uptake by Small Indian Mongooses (Herpestes auropunctatus) in Southwestern Puerto Rico. Journal of Wildlife Diseases 56:452-456.

Berentsen AR, Sugihara RT, Payne CG, Leinbach I, Volker SF, Vos A, Ortmann S \& Gilbert AT. 2019. Analysis of Iophenoxic Acid Analogues in Small Indian Mongoose (Herpestes Auropunctatus) Sera for Use as an Oral Rabies Vaccination Biological Marker. JoVE:e59373.

Bruce SJ, Tavazzi I, Parisod V, Rezzi S, Kochhar S \& Guy PA. 2009. Investigation of Human Blood Plasma Sample Preparation for Performing Metabolomics Using Ultrahigh Performance Liquid Chromatography/Mass Spectrometry. Analytical Chemistry 81:3285-3296.

Eason C, Batcheler D \& Frampton C. 1994. Comparative Pharmacokinetics of Iophenoxic Acid in Cats and Brushtail Possums. Wildlife Research 21:377-380.

Fisher P. 1999. Review of Using Rhodamine B as a Marker for Wildlife Studies. Wildlife Society Bulletin (1973-2006) 27:318-329.

Fisher PM \& Marks CA. 1997. Evaluation of Iophenoxic Acid as a Biomarker for Swamp Wallabies (Wallabia bicolor). Wildlife Research 24:97-103.

Flies AS, Flies EJ, Fox S, Gilbert A, Johnson SR, Liu GS, Lyons AB, Patchett AL, Pemberton D \& Pye RJ. 2020. An oral bait vaccination approach for the Tasmanian devil facial tumor diseases. Expert Review of Vaccines 19:1-10.

Jacoblinnert K, Imholt C, Schenke D \& Jacob J. 2021. Ethyl-iophenoxic acid as a quantitative bait marker for small mammals. Integrative Zoology:1-10. 
Müller TF, Schröder R, Wysocki P, Mettenleiter TC \& Freuling CM. 2015. Spatio-temporal Use of Oral Rabies Vaccines in Fox Rabies Elimination Programmes in Europe. PLOS Neglected Tropical Diseases 9:e0003953.

Philip J. 2020. A historical review of Australian aerial vertebrate pest control, targeting dingoes and wild dogs 1946 - 2019. Australian Zoologist 41:580-592.

Qureshi T, Drawe DL, Davis DS \& Craig TM. 1994. Use of bait containing triclabendazole to treat Fascioloides magna infections in free ranging white-tailed deer. Journal of Wildlife Diseases 30:346-350.

Tovar C, Pye RJ, Kreiss A, Cheng Y, Brown GK, Darby J, Malley RC, Siddle HV, Skjodt K, Kaufman J, Silva A, Baz Morelli A, Papenfuss AT, Corcoran LM, Murphy JM, Pearse MJ, Belov K, Lyons AB \& Woods GM. 2017. Regression of devil facial tumour disease following immunotherapy in immunised Tasmanian devils. Scientific Reports 7:43827.

Van Brackle MD, Linhart SB, Creekmore TE, Nettles VF \& Marchinton RL. 1994. Oral Biomarking of White-Tailed Deer with Tetracycline. Wildlife Society Bulletin (1973-2006) 22:483-488. 
bioRxiv preprint doi: https://doi.org/10.1101/2021.12.14.472710; this version posted December 16, 2021. The copyright holder for this preprint (which was not certified by peer review) is the author/funder, who has granted bioRxiv a license to display the preprint in perpetuity. It is made available under aCC-BY-NC-ND 4.0 International license.

\section{FIGURES}

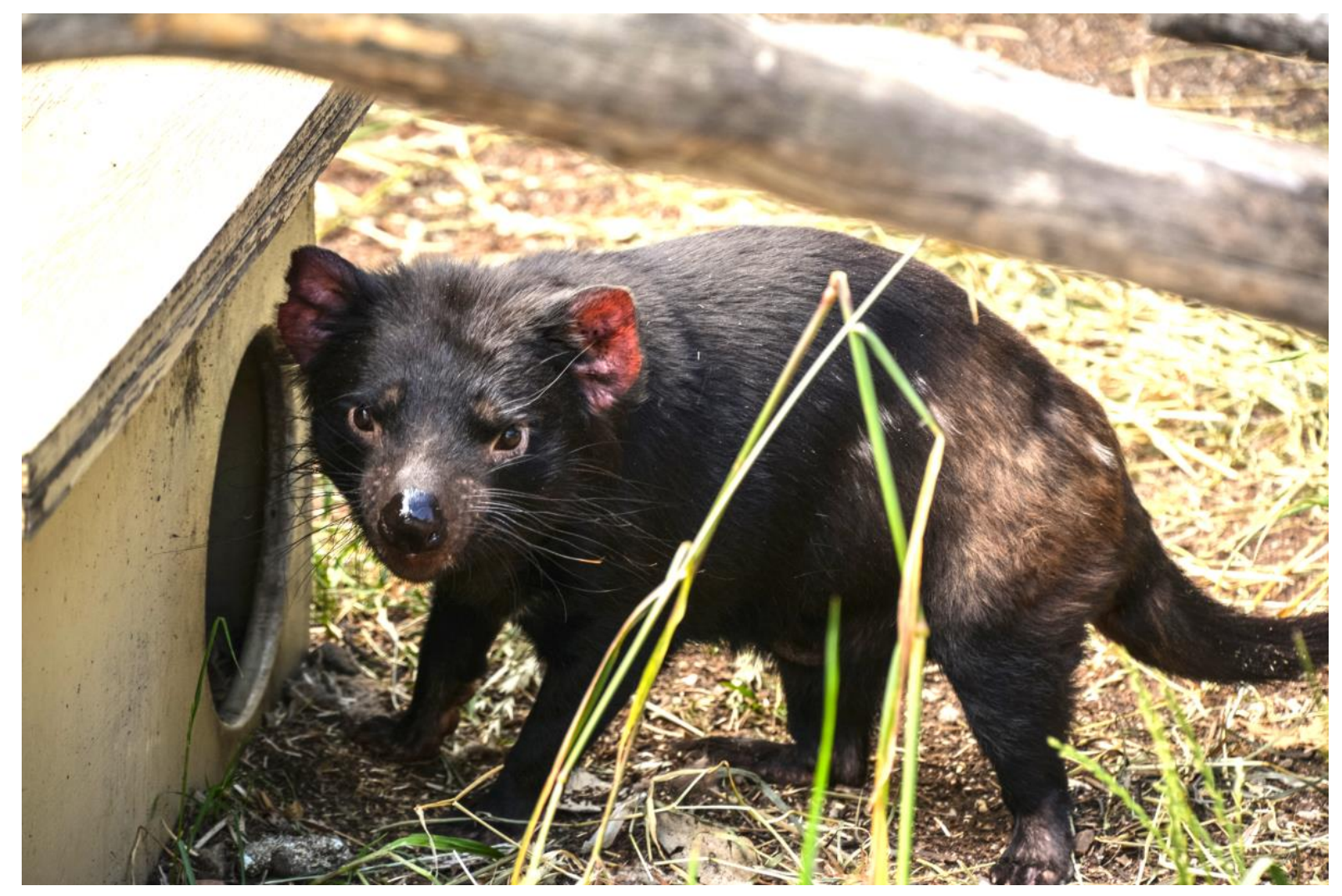

Figure 1. Photo of Tasmanian devil (Sarcophilus harrisii) (photo credit Greg Woods) 


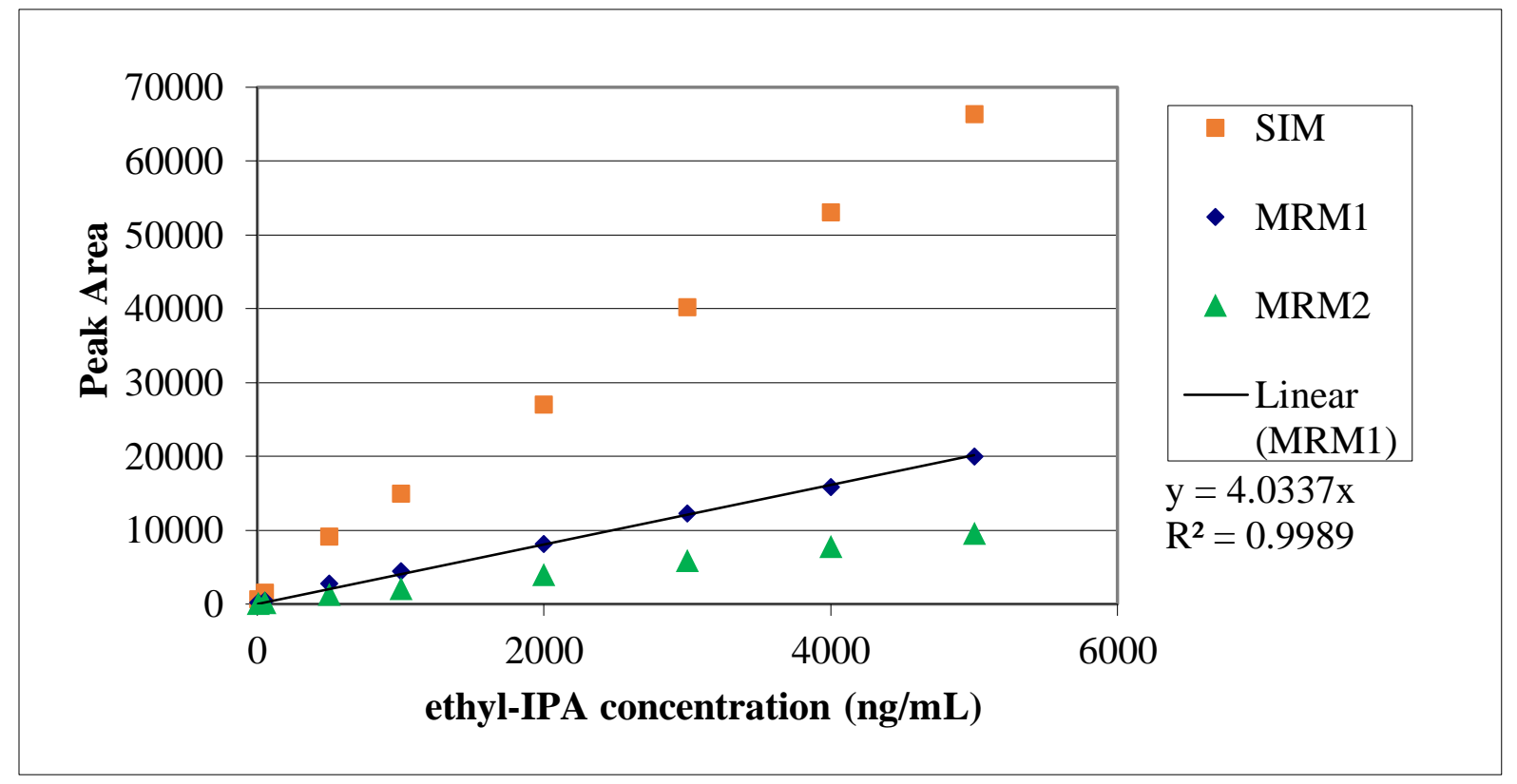

Figure 2. Three modes of analysis for detecting Ethyl-IPA in Tasmanian devil serum samples (day 1). First, single ion monitoring (SIM) detection of the Et-IPA precursor deprotonated molecular ion $[\mathrm{M}-\mathrm{H}]-(\mathrm{m} / \mathrm{z})$ 570.7. Second and third are the multiple reaction monitoring (MRM) $1 \& 2$ molecular transitions, where the precursor ion is then fragmented into two specific product ions, $(\mathrm{m} / \mathrm{z}) 442.8$ and 126.8 respectively. The MRM1 data is that used to undertake the actual calibration, and this is the data that is displayed for the samples. 
A.
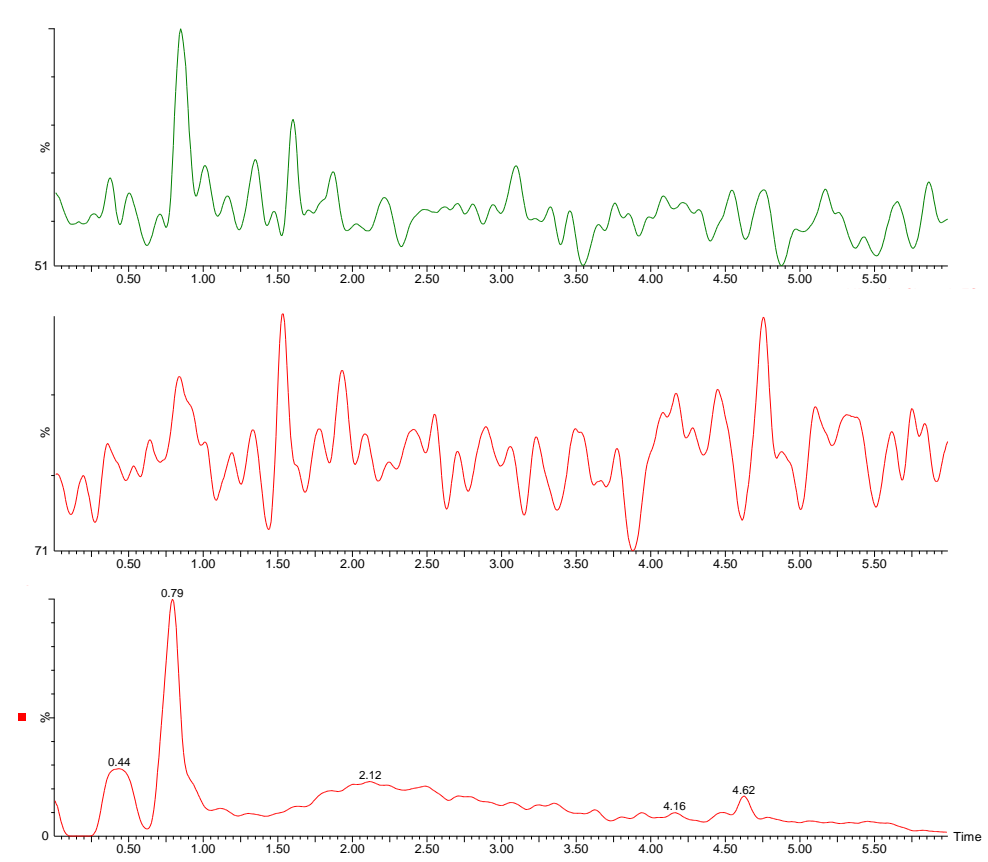

B.
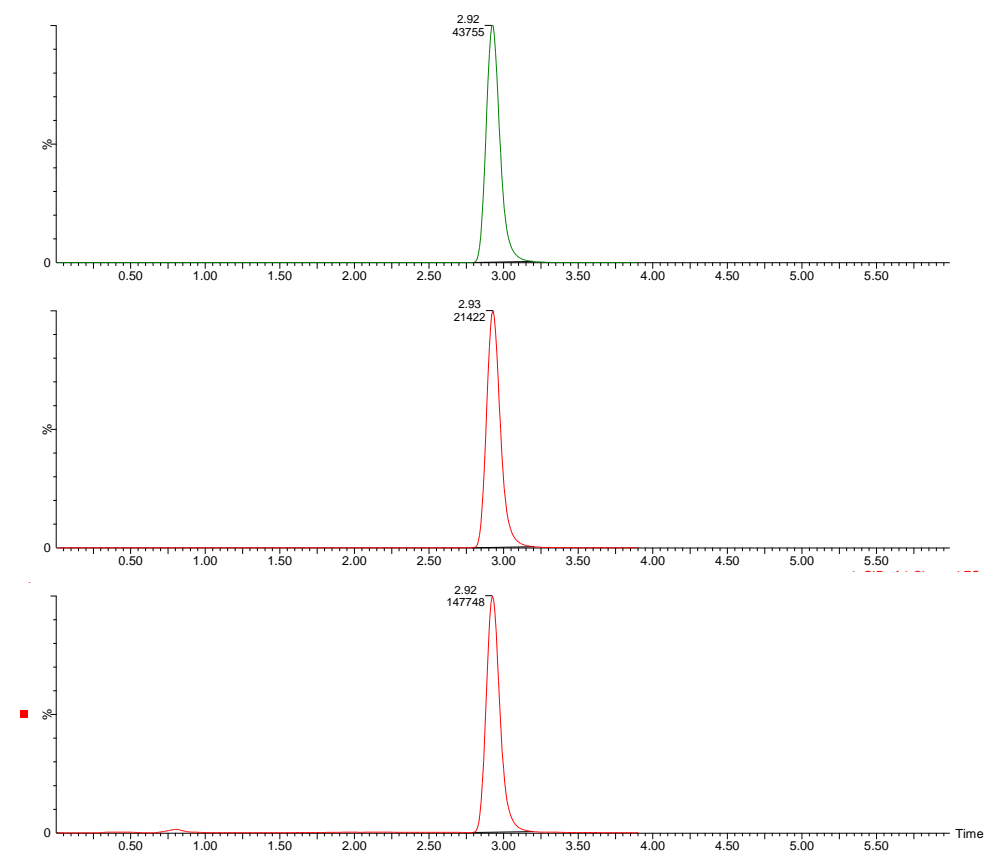

Figure 3. Chromatograms of serum from devil TD1: baseline (panel A), and 1 day postingestion of Et-IPA (panel B). For both panels, upper chromatogram represents MRM1 [MH]- (m/z) 570.7 to 442.8. Middle chromatogram represents MRM2 [M-H]- (m/z) 570.7 to 126.8 . Lower chromatogram represents $\operatorname{SIM~(m/z)~} 570.7$. 


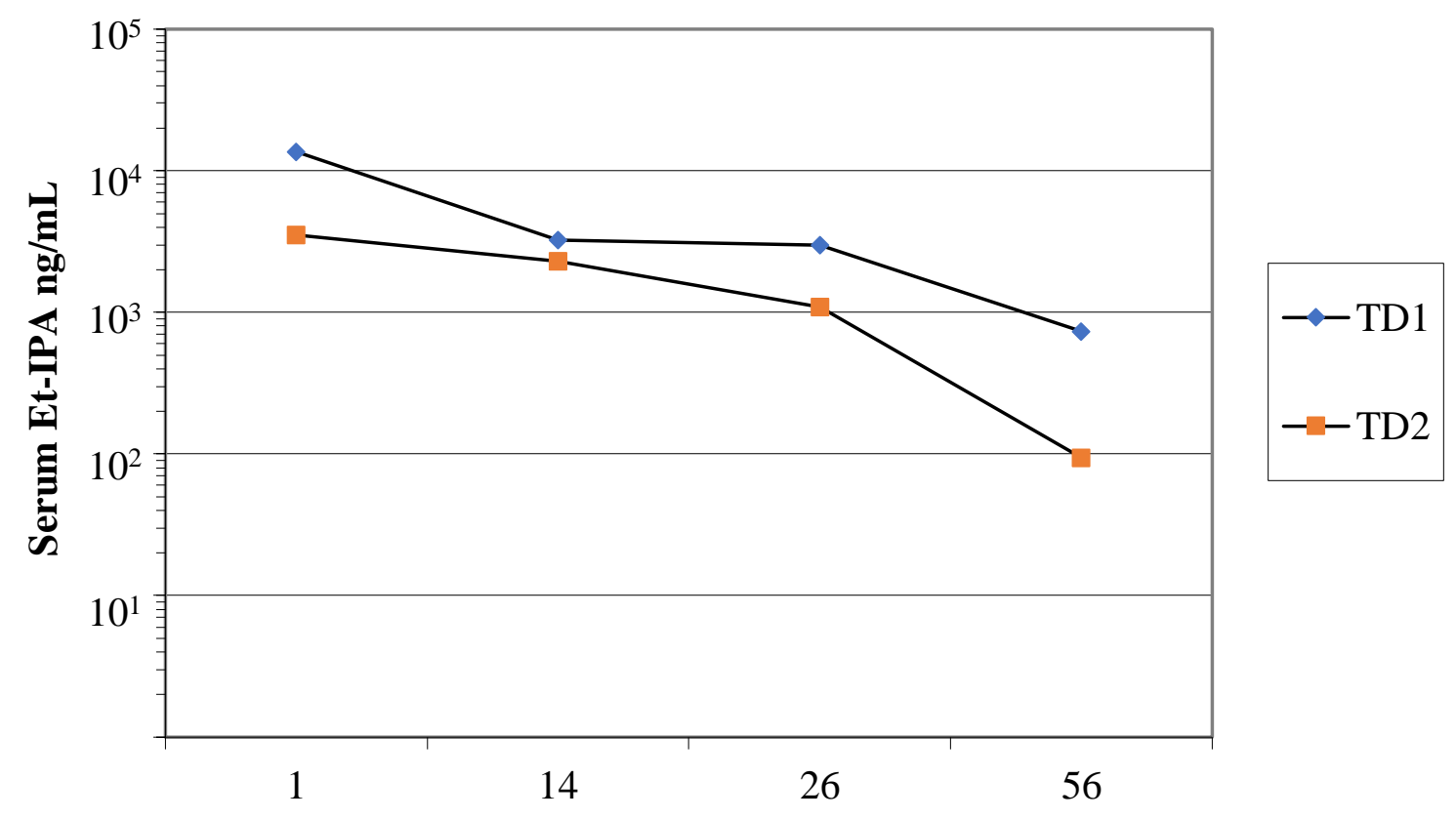

Days post Et-IPA ingestion

Figure 4. Serum concentration of Et-IPA in TD1 and TD2 over 8 weeks post-ingestion of

Et-IPA. Serum concentrations were measured in $\mathrm{ng} / \mathrm{mL}$ and shown on $\log _{10}$ scale 